\title{
Flail aortic valve leaflet due to high-voltage electrical injury
}

\section{(D) Josip Katić*, OMijo Meter, (C)Antonia Melada, Olvona Mustapić, (D) Viktoria Lišnić, Darija Baković Kramarić}

University Hospital Centre Split, Split, Croatia
RECEIVED:

February 28, 2019

ACCEPTED:

March 24, 2019

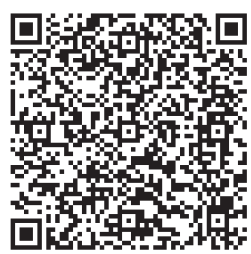

KEYWORDS: flail aortic valve leaflet, aortic regurgitation, electric injuries. CITATION: Cardiol Croat. 2019;14(3-4):85. | https://doi.org/10.15836/ccar2019.85

*ADDRESS FOR CORRESPONDENCE: Josip Katić, Klinički bolnički centar Split, Spinčićeva 1, HR-21000 Split, Croatia. / Phone: +385-91-5582-637 / E-mail: josipkati@gmail.com

ORCID: Josip Katić, https://orcid.org/0000-0002-4991-1919 • Mijo Meter, https://orcid.org/0000-0003-4674-426X Antonia Melada, https://orcid.org/0000-0003-4223-2582 • Ivona Mustapić, https://orcid.org/0000-0002-1534-3642 Viktoria Lišnić, https://orcid.org/0000-0001-7598-6749 • Darija Baković Kramarić, https://orcid.org/0000-0001-6751-5242

\section{||||||||||||||||||||||||||||||||||||||||||||||||||||||||||||||||||||||||||||||||||||||||||||||||||||||||||||||||||||||||||||||||||||||}

Introduction: Electric shock is the set of pathophysiological events resulting from the action of an electric current on the human body ${ }^{1}$. Electrical injuries involve both direct (caused by contact with electricity arc) and indirect mechanisms (mechanical trauma due to falls). The most common sequels after electrical injury in the heart are arrhythmias and myocardial contusion ${ }^{2}$. Large arteries like aorta are rarely affected because their rapid flow allows them to dissipate the heat produced by the electric current. However, they are susceptible to medial necrosis, with aneurysm formation and rupture at a later point of time. There is one case in the literature which described aortic valve rupture due to high-voltage electrical injury ${ }^{3}$.

Case report: 47-year-old male patient was admitted to our echo lab for ultrasound examination of the heart. In the last two months he had been complaining about exertional dyspnea. His medical history was quite poor: he had never been admitted to the hospital until two months ago when he had been observed for 24 hours after he had suffered a high-voltage electric injury. The transthoracic echocardiography was performed, and we discovered moderately enlarged left ventricle (LVED volume 180 $\mathrm{ml}$ ) due to severe aortic regurgitation on bicuspid aortic valve with holo-diastolic retrograde flow. The regurgitation jet that filled the two thirds of left ventricular outflow tract with laceration and flail of bicuspid cusps confirmed on transesophageal ultrasound. The patient underwent surgery. The aortic valve was removed and replaced with a mechanical prosthesis.

Conclusion: Cardiac symptoms and echocardiographic findings that initiated two months after a high-voltage electric injury led us to conclusion that bicuspid valve was probably injured by electrical shock. To the authors' knowledge, this is the first reported case of valvular rupture due to electrical injury in Croatian population.
LITERATURE IIIIIIIIIIIIIIIIIIIIIIIIIIIIIIIIIIIIIIIIIIIIIIIIIIIIIIIIIIIIIIIIIIIIIIIIIIIIIIIIIIIIIIIIIIIIIIIIIIIII 1. Koumbourlis AC. Electrical injuries. Crit Care Med. 2002 Nov;30(11 Suppl):S424-30. PubMed: https://www.ncbi.nlm.nih.gov/pubmed/12528784

2. Waldmann V, Narayanan $K$, Combes $N$, Jost D, Jouven X, Marijon E. Electrical cardiac injuries: current concepts and management. Eur Heart J. 2018 Apr 21;39(16):1459-1465. Eur Heart J. 2018 Apr 21;39(16):1459-1465. https://doi.org/10.1093/eurheartj/ehx142

3. Güler N, Ozkara C, Tuncer M, Güntekin U, Kocabas S. Aortic valve rupture due to high-voltage electrical injury: case report. J Heart Valve Dis. 2004 Sep;13(5):857-9. PubMed: https://www.ncbi.nlm.nih.gov/pubmed/15473491 